\title{
Kimyasal Banyo Depolama Yöntemi ile Üretilen PbS İnce Filmleri Üzerine Tavlamanın Etkileri
}

\author{
Ayça Kıyak Yıldırım* \\ ${ }^{1}$ Bilecik Şeyh Edebali Üniversitesi, Meslek YüksekOkulu, Motorlu Taşıtlar ve Ulaştırma Teknolojisi Bölümü, \\ Bilecik, TÜRKIYE \\ ${ }^{*}$ ayca.kiyak@bilecik.edu.tr
}

(Geliş/Received: 23/05/2019;

Kabul/Accepted: 10/05/2020)

Öz: Bu çalışmada hem sodyum sülfit kullanılarak hem de sodyum sülfit kullanılmadan kimyasal banyo depolama metodu ile $\mathrm{PbS}$ ince filmleri üretilmiştir. Üretilen filmler $400{ }^{\circ} \mathrm{C}$ 'de tavlanmıştır. Tavlanan $\mathrm{PbS}$ ince filmlerin karakterizasyonu taramalı elektron mikroskobu (SEM) ve X-ışını kırınımı (XRD) yöntemleri kullanılarak gerçekleştirilmiştir. XRD verilerinden, tavladıktan sonra pik şiddetlerinin arttığı gözlenmiştir. Tavlama ile filmlerin yüzey yapılarının tamamen değiştiği ve deliklerin kaybolduğu gözlenmiştir.

Anahtar kelimeler: Tavlama, PbS, kimyasal banyo depolama yöntemi, ince film.

\section{The Effects of Annealing on PbS Thin Films Produced by Chemical Bath Deposition Method}

Abstract: In this study, two films were produced by both using sodium sulphide and without sodium sulphide. The produced films were annealed at $400{ }^{\circ} \mathrm{C}$. From the XRD data, it was observed that the intensity of the peaks increased after the annealing. The surface structures of the films were examined with a SEM instrument. With annealing it was understood that the surface structures of the films were completely changed and the holes were disappeared.

Key words: Annealing, $\mathrm{PbS}$, chemical bath deposition, thin film.

\section{Giriş}

PbS, 300 K'de 0,41 eV'lik dar bant aralı̆̆g ve 18 nm'lik yeterli büyüklükte bir Bohr yarıçapına sahip olan en önemli IV-VI yarı iletkenlerden biridir. Böylece, kristalit büyüklüğünü kontrol ederek bant aralığı değerini düzenleyen güçlü kuantum ve elektron hapsi sağlar [1]. Absorpsiyon katsayısı $105 \mathrm{~cm}-1$ 'den büyüktür ve katkılama ile hem $\mathrm{p}$ tipi hem de $\mathrm{n}$ tipi olarak üretilebilir.

$\mathrm{PbS}$ uygun maliyetli fotovoltaikler için, sürdürülebilir bir materyal olarak da önerilmiştir [2]. Bu materyal, kızılötesi detektör uygulamaları için çok önemlidir. $\mathrm{PbS}$ ayrıca iyonik sensör, güneş emilimi, güneş kontrol kaplamaları ve diyot lazerleri gibi çeşitli uygulamalarda da kullanılmaktadır [3].

Değişen büyüklükteki $\mathrm{PbS}$ nanoparçacıklı ince filmlerin kontrolü üzerine birçok araştırma yapılmıştır. Hem fiziksel hem de kimyasal biriktirme yöntemleri kullanılmıştır. Vakumla buharlaşma [4], sıcak duvar epitaksi [5], moleküler 1şın epitaksi [5] ve darbeli lazer birikimi [6], PbS sentezi için en başarılı fiziksel yöntemler arasındadır. En yaygın olarak kullanılan kimyasal biriktirme yöntemleri arasında sprey piroliz [7,8], kimyasal banyo depolama yöntemi (CBD) [9-17], ardışı iyonik tabaka adsorpsiyonu ve reaksiyonu (SILAR) [18], elektrokimyasal depozisyon [19-21] ve hidrotermal yöntem sayılabilir [22].

Daha önceki yıllarda yapılan bir çalışmada, $\mathrm{Pb}\left(\mathrm{NO}_{3}\right)_{2}, \mathrm{NaOH}, \mathrm{SC}\left(\mathrm{NH}_{2}\right)_{2}$ ve $\mathrm{H}_{2} \mathrm{O}$ kullanılarak sabit oda sıcaklığında farklı konsantrasyon ve daldırma sürelerinde $\mathrm{PbS}$ ince filmlerin üretimi gerçekleştirilmiştir. Büyütme parametrelerinin değişiminin ve ssıl işlemin $\mathrm{PbS}$ ince filmlerinin yapısını, morfolojisini ve optik özelliklerini etkilediği gözlenmiştir [23]. Yapılan başka bir çalışmada, $\mathrm{PbS}$ ince filmler $50{ }^{\circ} \mathrm{C}$ ve $80{ }^{\circ} \mathrm{C}$ kimyasal banyo depolama sıcaklığında cam alt taban üzerine büyütülmüştür. XRD, SEM ve EDAX gibi çeşitli teknikler kullanılarak $\mathrm{PbS}$ ince filmlerin karakterizasyonu yapılmıştır. SEM analizi üretilen ince fillmlerin yüzeyinin pürüzsüz olduğunu ve cam yüzeyini tamamen kapladığını göstermiştir. Ayrıca EDAX sonuçları ince filmlerin $\mathrm{Pb}$ açısından zengin olduğunu göstermiştir [24]. Önceki çalışmaların bir diğerinde, $\mathrm{PbS}$ ince filmler $35^{\circ} \mathrm{C}$ kimyasal banyo depolama sıcaklığında ve farklı daldırma sürelerinde büyütülmüştür. Üretilen filmlerin yüzey analizleri incelendiğinde daldırma süreleri arttıkça tanecik büyüklüğünün ve yüzey homojenliğinin arttığı belirlenmiştir

\footnotetext{
* Ayça Kıyak Yıldırım: ayca.kiyak@ bilecik.edu.tr ORCID Numarası: ${ }^{1} 0000-0002-8339-947 X$
} 
[25]. Kimyasal banyo depolama yöntemi pratik olarak basittir, geniş alana uygundur ve hatta plastik alt tabakaları oda sıcaklığında kaplayabilir [2].

PbS'nin kimyasal çöktürme reaksiyonları aşağıda verilmiştir [26]:

$$
\begin{aligned}
& \mathrm{Pb}\left(\mathrm{NO}_{3}\right)_{2}+2 \mathrm{NaOH} \rightarrow \mathrm{Pb}(\mathrm{OH})_{2}+2 \mathrm{NaNO}_{3} \\
& \mathrm{~Pb}(\mathrm{OH})_{2}+2 \mathrm{NaOH} \rightarrow \mathrm{Na}_{2}\left[\mathrm{~Pb}(\mathrm{OH})_{4}\right] \\
& {\left[\mathrm{Pb}(\mathrm{OH})_{4}\right]^{2-} \rightarrow \mathrm{Pb}^{2+}+4 \mathrm{OH}^{-}} \\
& \mathrm{CS}\left(\mathrm{NH}_{2}\right)_{2}+\mathrm{OH}^{-} \rightarrow \mathrm{CH}_{2} \mathrm{~N}_{2}+\mathrm{H}_{2} \mathrm{O}+\mathrm{HS}^{-} \\
& \mathrm{HS}^{-}+\mathrm{OH}^{-} \rightarrow \mathrm{H}_{2} \mathrm{O}+\mathrm{S}^{2-} \\
& \mathrm{Pb}^{2+}+\mathrm{S}^{2-} \rightarrow \mathrm{PbS}
\end{aligned}
$$

2016 yılında Ramírez-Ceja ve ark. tarafından yapılan bir çalışmada da, $\mathrm{PbS}$ ince filmler üzerine tavlamanın etkileri araştırılmıştır. Fakat bahsedilen bu çalışmada $200{ }^{\circ} \mathrm{C}$ ve $300{ }^{\circ} \mathrm{C}$ de filmler tavlanmıştır [27]. Bu çalışmada ise, $\mathrm{PbS}$ ince filmler üzerine $400^{\circ} \mathrm{C}$ 'de tavlamanın etkileri ilk defa araştırıldı. Filmlerin XRD sonuçları tavlama ile kristallenmenin arttı̆̆ını gösterdi. Ek olarak, literatürde kimyasal banyo depozisyon yöntemi ile sodyum sülfit $\left(\mathrm{Na}_{2} \mathrm{SO}_{3}\right)$ bileşiği kullanılarak $\mathrm{PbS}$ üretimi ile ilgili çalışmalar incelendi [28]. $\mathrm{Na}_{2} \mathrm{SO}_{3}$ kullanıldığında daha compakt ve iyi kristallenmiş filmler elde edildiği gözlendiği için, yapılan bu çalışmada $\mathrm{Na}_{2} \mathrm{SO}_{3}$ bileşiği tercih edildi. Ayrıca, üretilen filmlerin SEM görüntülerinden filmlerin yüzey yapılarının tamamen değiştiği ve deliklerin kaybolduğu gözlendi.

\section{Materyal ve Yöntem}

$\mathrm{PbS}$ ince filmler kimyasal olarak temizlenmiş alt taban üzerine depolandı. Hazırlık aşamasında, alt taban olarak seçilen cam yüzeyler nitrik asit ve izopropil alkol kullanılarak temizlendi. Bu işlemden sonra cam yüzeyler damıtılmış su ile yıkandı. $\mathrm{PbS}$ ince filmlerinin üretilmesi için kimyasal banyo çözeltisi100mL deiyonize su kullanılarak hazırlandı. İlk olarak 0,0089 $\mathrm{M}$ kurşun nitrat $\left(\mathrm{Pb}\left(\mathrm{NO}_{3}\right)_{2}\right)$ ve $0,15 \mathrm{M}$ sodyum hidroksit $(\mathrm{NaOH})$ bileşikleri birbirine karıştırıldı. Kimyasal banyo çözeltisinin önce süt beyazı renge döndüğü gözlendi. Daha sonra NaOH'ın tamamen çözünmesiyle banyo çözeltisinin berraklaştığı görüldü. Berrak olan bu çözeltiye $0,051 \mathrm{M}$ tiyoüre $\left(\mathrm{CS}\left(\mathrm{NH}_{2}\right)_{2}\right)$ bileşiği karıştırıldı. Bu karışım kullanılarak üretilen film Set1 olarak isimlendirildi. Bir diğer deneyde ise, Set1 için hazırlanan çözeltiye $0,00023 \mathrm{M}$ sodyum sülfit $\left(\mathrm{Na}_{2} \mathrm{SO}_{3}\right)$ bileşiği eklendi. Yeni karışım kullanılarak üretilen filme ise Set2 adı verildi.

Tüm üretimler, $25^{\circ} \mathrm{C}$ 'de gerçekleştirildi. $\mathrm{Na}_{2} \mathrm{SO}_{3}$ kullanılmadan yapılan fillm üretimi 35 dakika ve kullanılarak yapılan film üretimi ise 90 dakika sürdü. Çünkü $\mathrm{Na}_{2} \mathrm{SO}_{3}$ inhibitördür ve kimyasal banyo çözeltisinde gerçekleşecek olan reaksiyonun yavaşlamasına neden olmaktadır. Kimyasal banyo depolama işlemi sırasında banyo duvarına bakan alt tabaka yüzeyi incelemek için kullanıldı ve damıtılmış suyla iyice yıkanarak hava ortamında kurutuldu. Ancak diğer yüzey, \%10 seyreltik hidroklorik asit ile temizlendi.

Üretilen PbS ince filmlerin yapısal özelliklerini analiz etmek için PANalytical Empyrean XRD (X-1şını kırınım ölçeri) kullanıldı. PbS ince filmlerinin kalınlıkları, gravimetrik yöntem kullanılarak hesaplandı. PbS ince filmlerin yüzey morfolojisini analiz etmek için ise, Zeiss SUPRA 40VP SEM (taramalı elektron mikroskopu) kullanıldı. Elde edilen filmlerin XRD ve SEM sonuçları incelendi. Daha sonra aynı filmler $400^{\circ} \mathrm{C}^{\prime} \mathrm{de}$ bir kül fırınında atmosfer altında tavlandı ve ardından tekrar XRD ve SEM sonuçlarına bakıldı.

\section{Sonuçlar}

\subsection{Elde edilen PbS ince filmlerinin yapısal özellikleri}

XRD tekniği ile üretilen PbS ince filmlerin kristal yapısı, tane büyüklüğü, tercihli yönelimi, deformasyonu (strain) ve birim yüzeye etki eden kuvvet gerilimi (stres) gibi özellikleri belirlendi.

Şekil 1'de üretilen $\mathrm{PbS}$ ince filmlerin XRD analizleri verildi. Üretilen filmlerde $25,9^{\circ} ; 30^{\circ} ; 43^{\circ} ; 50,9^{\circ}$;

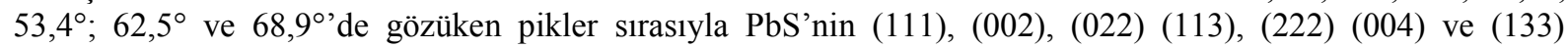


düzlemlerine aittir. Bu pikler incelenerek (98-060-0243) numaralı ASTM kartı ile uyumlu oldukları tespit edildi. XRD analizlerinde, bütün filmlerin kübik yapıda oldukları bulundu.

Üretilen PbS ince filmleri için film kalınlıkları gravimetrik yöntemle hesaplandı. Tavlama işleminden önceki film kalınlığı ile tavlama işleminden sonraki film kalınlıklarının çok az değiştiği görüldü ve bu değişim ihmal edildi. Bütün filmlerin yaklaşık $650 \mathrm{~nm}$ kalınlığında oldukları belirlenerek Tablo 1'de verildi. Elde edilen fillmlerin XRD desenleri incelendiğinde, tavlama işleminden sonra XRD pik şiddetlerinin arttığı görüldü. Filmler tavlandığında tanecikler arası boşluklar neredeyse kapanacağı için bu durumun tavlama sonrası film kalınlıklarında azalmaya neden olduğu, fakat XRD de daha yüksek pik şiddeti görülmesine sebep olduğu düşünülmektedir. Ancak bu çalışmada, film kalınlıkları yaklaşık olarak aynı kabul edildiği için, XRD pik şiddetlerin artmasının fillmlerdeki kristallenmenin artmasıyla sonuçlandığı düşünülmektedir.

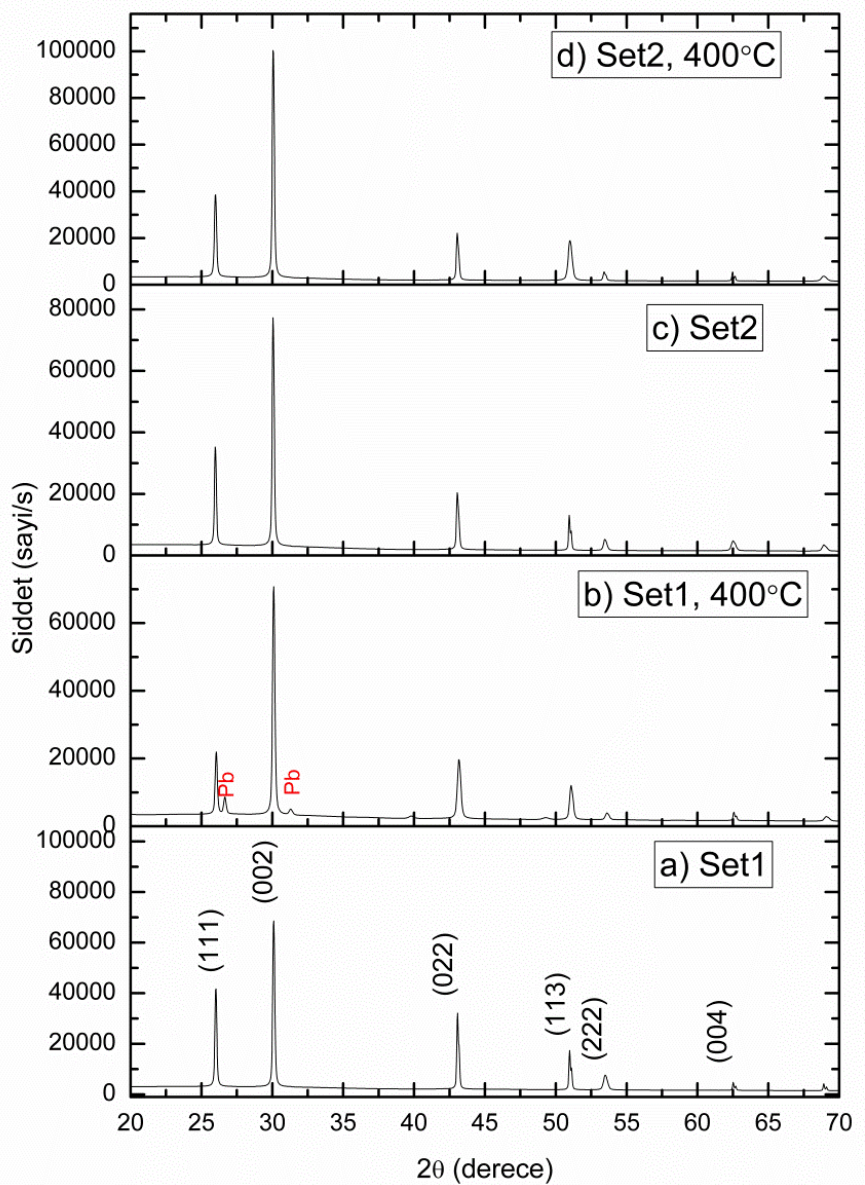

Şekil 1. Üretilen PbS ince filmlerin XRD analizleri

Üretilen $\mathrm{PbS}$ ince filmlerin tercihli yönelimini belirlenmesi için yapılanma katsayısı TC (Texturecoefficient) kullanıldı. Eğer yapılanma katsayısı değeri 1'den büyük bir den fazla yansıma düzlemi mevcut ise, tek bir tercihli yönelimden bahsedilemez [29]. Üretilen $\mathrm{PbS}$ ince filmlerin yapılanma katsayısı değeri, herhangi bir (hkl) yansıma düzlemi için Denklem 7 kullanılarak

$T C=\frac{I_{(h k l)} / I_{0(h k l)}}{\frac{1}{N} \sum_{N}\left(\frac{I_{(h k l)}}{I_{0(h k l)}}\right)}$

hesaplandı. Hesaplanan değerler Tablo 1'de verildi. Burada $\mathrm{I}_{(\mathrm{hkl})}$; (hkl) düzlemlerinin ölçülen göreli yoğunluğu, $\mathrm{I}_{0(\mathrm{hkl})}$; ASTM kartında verilen (hkl) düzlemlerinin standart yoğunluğudur. Tablo 1 incelendiğinde tavlama 
işleminden sonra yapılanma katsayısı değeri 1'den büyük tek bir yansıma düzleminin mevcut olduğu görüldü. Bu düzlem, 30'de gözüken $\mathrm{PbS}$ pikine karşılık gelen (002) düzlemidir.

Tablo 1. Elde edilen PbS ince filmlerin XRD şiddetleri, hesaplanan yapılanma katsayısı değerleri ve gravametrik analiz kullanarak hesaplanan film kalınlıkları

\begin{tabular}{|c|c|c|c|c|c|c|}
\hline 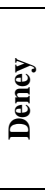 & $\stackrel{\sim}{\sim}$ & 昰 & $\doteq$ & $\underset{H}{U}$ & $\frac{\widehat{I}}{\mathfrak{s}}$ & 思害 \\
\hline \multirow{7}{*}{$\overline{\mathscr{\nu}}$} & 25,993 & 41291,2 & 56,71 & 1,54 & (111) & \multirow{7}{*}{645} \\
\hline & 30,078 & 66868,49 & 100 & 2,71 & (002) & \\
\hline & 43,065 & 32087,6 & 53,41 & 1,45 & $(022)$ & \\
\hline & 50,978 & 17347,38 & 28,46 & 0,78 & (113) & \\
\hline & 53,467 & 7584,869 & 8,6 & 0,23 & (222) & \\
\hline & 62,523 & 4817,229 & 5,97 & 0,16 & (004) & \\
\hline & 68,91 & 4234,824 & 5,27 & 0,14 & (133) & \\
\hline \multirow{7}{*}{ 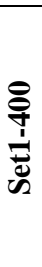 } & 26,022 & 18653,51 & 26,27 & 0,71 & (111) & \multirow{7}{*}{634} \\
\hline & 30,077 & 69016,71 & 100 & 2,71 & $(002)$ & \\
\hline & 43,144 & 16521,76 & 25,48 & 0,69 & $(022)$ & \\
\hline & 51,058 & 8023,417 & 16,08 & 0,44 & (113) & \\
\hline & 53,589 & 2855,856 & 3,14 & 0,09 & (222) & \\
\hline & 62,567 & 4130,623 & 4,49 & 0,12 & $(004)$ & \\
\hline & 69,067 & 2556,682 & 2,11 & 0,06 & (133) & \\
\hline \multirow{7}{*}{ ֶ) } & 25,961 & 34175,9 & 41,08 & 1,11 & (111) & \multirow{7}{*}{650} \\
\hline & 30,040 & 73546,52 & 100 & 2,71 & $(002)$ & \\
\hline & 43,049 & 19548,21 & 28,01 & 0,76 & $(022)$ & \\
\hline & 50,954 & 13051,41 & 18,79 & 0,51 & (113) & \\
\hline & 53,448 & 5214,493 & 5,11 & 0,14 & (222) & \\
\hline & 62,490 & 4731,507 & 4,5 & 0,12 & (004) & \\
\hline & 68,900 & 3439,045 & 2,92 & 0,08 & (133) & \\
\hline \multirow{7}{*}{ 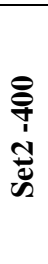 } & 25,965 & 38498,3 & 32,77 & 0,89 & (111) & \multirow{7}{*}{641} \\
\hline & 30,047 & 99564,87 & 100 & 2,71 & (002) & \\
\hline & 43,042 & 20397,5 & 22,37 & 0,61 & $(022)$ & \\
\hline & 50,974 & 18668,71 & 16,56 & 0,45 & (113) & \\
\hline & 53,406 & 5500,098 & 4,3 & 0,12 & (222) & \\
\hline & 62,476 & 4004,106 & 4,93 & 0,13 & (004) & \\
\hline & 68,871 & 3660,829 & 2,13 & 0,06 & (133) & \\
\hline
\end{tabular}

Elde edilen ince filmlerin tane büyüklüğü Denklem 8'de verilen Scherrer formülü ile hesaplandı ve Tablo 2'de verildi.

$D=\frac{0,9 \lambda}{B(\text { radyan }) \cos \left(\theta_{B}\right)}$

burada D tane büyüklüğü, $\lambda$ kırınımda kullanılan X-ışınının dalga boyu, $B$ dikkate alınan pikin yarı maksimumundaki genişliği, $\theta_{\mathrm{B}}$ dikkate alınan pikin Bragg yansıma açısıdır [30]. Tane büyüklüğü arttıkça, elde edilen X-ışınlarının kırınım deseninde yansıyan ışınların şiddetini gösteren piklerin de daraldığı görüldü.

Kübik kaya tuzu yapısının örgü parametresi Denklem 9 kullanılarak hesaplandı ve Tablo 2 de verildi.

$a=d \sqrt{\left(h^{2}+k^{2}+l^{2}\right)}$

burada $h, k$ ve $l$ Miller indisleri, $d$ ise düzlemler arası mesafedir [31].

Ayrıca tüm düzlemler için ortalama stres (gerilme) ve mikro strain (gerginlik) ve sırasıyla Denklem 10 ve Denklem 11 kullanılarak 
$S=\varepsilon Y /(2 \sigma)$

$\varepsilon=\left(a_{0}-a\right) / a_{0}$

hesaplandı ve Tablo 2'de verildi. Burada; $\sigma$ bulk kristalinin Poisson oranı, a a bulk örneğinin örgü parametresi, a ince film numunelerinin örgü parametresinin düzeltilmiş değeri ve $\mathrm{Y}$ ise Young modülüdür. $\mathrm{PbS}$ için $\mathrm{Y}$ 'nin değeri 70,2GPa ve $\sigma$ değeri ise 0,28 olarak alınmaktadır.

Tablo 2. Üretilen PbS ince filmlerin tane büyüklükleri, dislokasyon yoğunlukları, doğrulanan örgü parametreleri, mikro strain değerleri ve ortalama gerilme değerleri

\begin{tabular}{|c|c|c|c|c|c|c|}
\hline Deney & $2 \theta$ & $\begin{array}{c}\text { Tane } \\
\text { Büyüklüğgü } \\
(\mathbf{n m})\end{array}$ & $\begin{array}{c}\text { Örgü } \\
\text { Parametresi } \\
\text { a (Doğrulanan) } \\
(\AA)\end{array}$ & $\begin{array}{c}\text { Mikro } \\
\text { Strain } \\
* 10^{-3}\end{array}$ & $\begin{array}{c}\text { Dislokasyon } \\
\text { Yoğunluğu } \\
(\text { çizgi/m²)*10 }\end{array}$ & $\begin{array}{c}\text { Ortalama } \\
\operatorname{Stres}\left(10^{8} \mathbf{N} / \mathbf{m}^{2}\right)\end{array}$ \\
\hline \multirow{7}{*}{ हैं } & 25,993 & 63,01 & 5,94038 & 0,738 & 2,52 & 0,93 \\
\hline & 30,078 & 63,58 & 5,94538 & 1,580 & 2,47 & 1,98 \\
\hline & 43,065 & 82,52 & 5,94261 & 1,114 & 1,47 & 1,4 \\
\hline & 50,978 & 85,04 & 5,93954 & 0,597 & 1,38 & 0,75 \\
\hline & 53,467 & 34,37 & 5,94055 & 0,767 & 8,46 & 0,96 \\
\hline & 62,523 & 89,80 & 5,94336 & 1,24 & 1,24 & 1,55 \\
\hline & 68,91 & 93,10 & 5,94035 & 0,733 & 1,15 & 0,92 \\
\hline \multirow{7}{*}{ 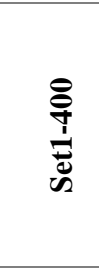 } & 26,022 & 52,51 & 5,93099 & $-0,844$ & 3,63 & $-1,06$ \\
\hline & 30,077 & 52,97 & 5,94254 & 1,102 & 3,56 & 1,38 \\
\hline & 43,144 & 20,63 & 5,93065 & $-0,902$ & 23,49 & $-1,13$ \\
\hline & 51,058 & 37,79 & 5,93298 & $-0,509$ & 7,00 & $-0,64$ \\
\hline & 53,589 & 42,98 & 5,92431 & $-1,970$ & 5,41 & $-2,47$ \\
\hline & 62,567 & 39,90 & 5,9386 & 0,4380 & 6,28 & 0,55 \\
\hline & 69,067 & 74,53 & 5,92784 & $-1,374$ & 1,80 & $-1,72$ \\
\hline \multirow{7}{*}{ ָे๊ } & 25,961 & 63,01 & 5,94481 & 1,485 & 2,52 & 1,86 \\
\hline & 30,040 & 63,57 & 5,94966 & 2,301 & 2,47 & 2,88 \\
\hline & 43,049 & 66,00 & 5,94315 & 1,204 & 2,30 & 1,51 \\
\hline & 50,954 & 85,03 & 5,94429 & 1,396 & 1,38 & 1,75 \\
\hline & 53,448 & 42,95 & 5,93879 & 0,4694 & 5,42 & 0,59 \\
\hline & 62,490 & 35,91 & 5,94512 & 1,536 & 7,76 & 1,93 \\
\hline & 68,900 & 37,37 & 5,94044 & 0,748 & 7,16 & 0,94 \\
\hline \multirow{7}{*}{ 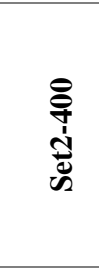 } & 25,965 & 52,50 & 5,94364 & 1,286 & 3,63 & 1,61 \\
\hline & 30,047 & 63,57 & 5,94832 & 2,075 & 2,47 & 2,60 \\
\hline & 43,042 & 66,00 & 5,94405 & 1,357 & 2,30 & 1,70 \\
\hline & 50,974 & 34,01 & 5,94210 & 1,027 & 8,65 & 1,29 \\
\hline & 53,406 & 57,27 & 5,94301 & 1,181 & 3,05 & 1,48 \\
\hline & 62,476 & 89,78 & 5,9464 & 1,752 & 1,24 & 2,20 \\
\hline & 68,871 & 26,58 & 5,94266 & 1,122 & 14,2 & 1,41 \\
\hline
\end{tabular}

Nelson-Riley grafikleri kullanılarak, örgü parametresinin düzeltilmiş değerleri hesaplandı. Üretilen ince filmlerin hesaplanan örgü parametreleri Denklem 12'de verilen F( $\theta)$ 'ya karşılık çizildi. Şekil 2 ve Şekil 3'de verildi

$F(\theta)=\left(\cos ^{2} \theta / 2\right) *\left(\frac{1}{\sin ^{2} \theta}+\frac{1}{\theta}\right)$

ve doğrusal çizgiyi kestiği nokta olan Denklem 13

$\left(\cos ^{2} \theta / 2\right) *\left(\frac{1}{\sin ^{2} \theta}+\frac{1}{\theta}\right)=0$

düzeltilmiş örgü parametresinin bulunmasını sağladı [32] ve Tablo 2'de verildi. 
Üretilen filmlerin dislokasyon yoğunluğu, Denklem 14 verildiği gibi

$\delta=\frac{1}{(c s)^{2}}$

tane boyutundan türetildi [32]ve Tablo 2'de verildi.

Tablo 2 incelendiğinde, Set1 ve Set2'den elde edilen ince filmlerin ortalama stres değerlerinin sirasılyla 0,75 $\times 10^{14}-1,98 \times 10^{14}\left(\right.$ çizgi $\left./ \mathrm{m}^{2}\right)$ ile $0,59 \times 10^{14}-2,88 \times 10^{14}\left(\right.$ çizgi $\left./ \mathrm{m}^{2}\right)$ arasında değişti. Set1'den elde edilen filme tavlama işlemi uygulandıktan sonra, negatif stres değerleri hesaplandı. Bunun hesaplanan negatif mikro straine [33] bağlı olarak PbS ince film üretimi esnasında meydana gelen baskı ve sıkışma gerginliğinden kaynaklandığı düşünülmektedir. Set1'den elde edilen filme tavlama işlemi uygulandıktan sonra ise, ortalama stres değerlerinin $1,29 \times 10^{14}-2,60 \times 10^{14}\left(c ̧ i z g i / \mathrm{m}^{2}\right)$ arasında değiștiği hesaplandı.
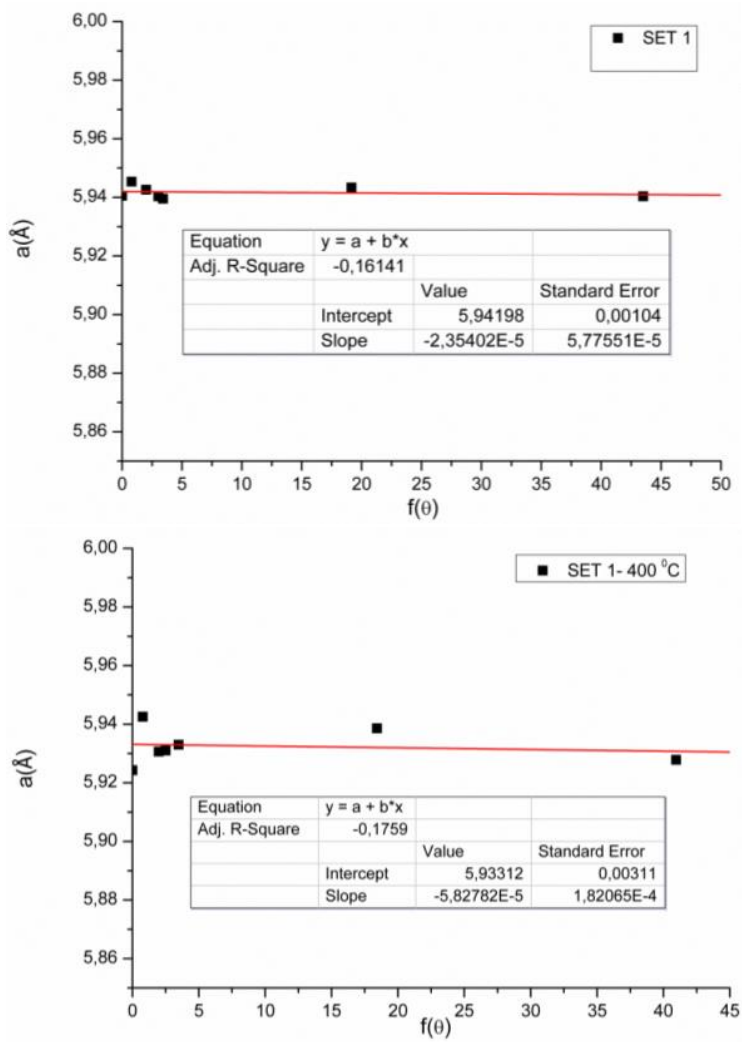

Şekil 2.Set 1 kullanılarak üretilen $\mathrm{PbS}$ ince filmlerin Nelson-Riley grafikleri
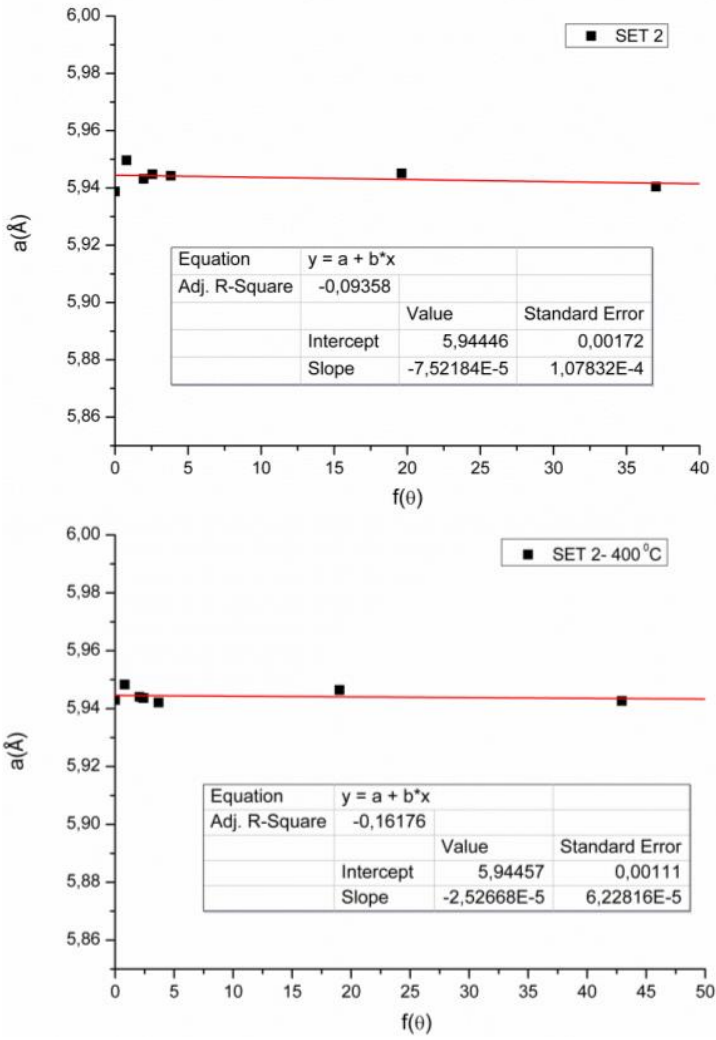

Şekil 3. Set 2 kullanılarak üretilen $\mathrm{PbS}$ ince filmlerin Nelson-Riley grafikleri

\subsection{Elde edilen PbS ince filmlerinin SEM analizleri}

Elde edilen PbS ince filmlerinin 100 büyütmedeki ve 30000 büyütmedeki SEM görüntüleri Şekil 4 ve Şekil 5 'de sirasiyla verilmektedir.

Şekil 4'de yer alan bütün $\mathrm{PbS}$ ince filmlerinin 100 kat büyütmeleri incelendiğinde Set1 ve Set2'den elde edilen $\mathrm{PbS}$ ince filmlerinin yüzeylerinde delikler olduğu görülmektedir. Ancak Set2'den elde edilen filmin yüzeyindeki delikler Set1'den elde edilen filme göre daha azdır.

Set1'den elde edilen filme $400{ }^{\circ} \mathrm{C}$ 'deki tavlama işlemi uygulandıktan sonra, ince filmin yüzeyindeki deliklerin kaybolmadığ 1 görülmektedir. $\mathrm{Na}_{2} \mathrm{SO}_{3}$ inhibitör eklenerek üretilen Set2 isimli ince filme $400{ }^{\circ} \mathrm{C}$ 'de tavlama işlemi uygulandıktan sonra, ince filmin yüzeyindeki deliklerin kaybolduğu gözlendi. Bu filmin kompakt, deliksiz ve çatlaksız bir ince film olduğu görüldü. 


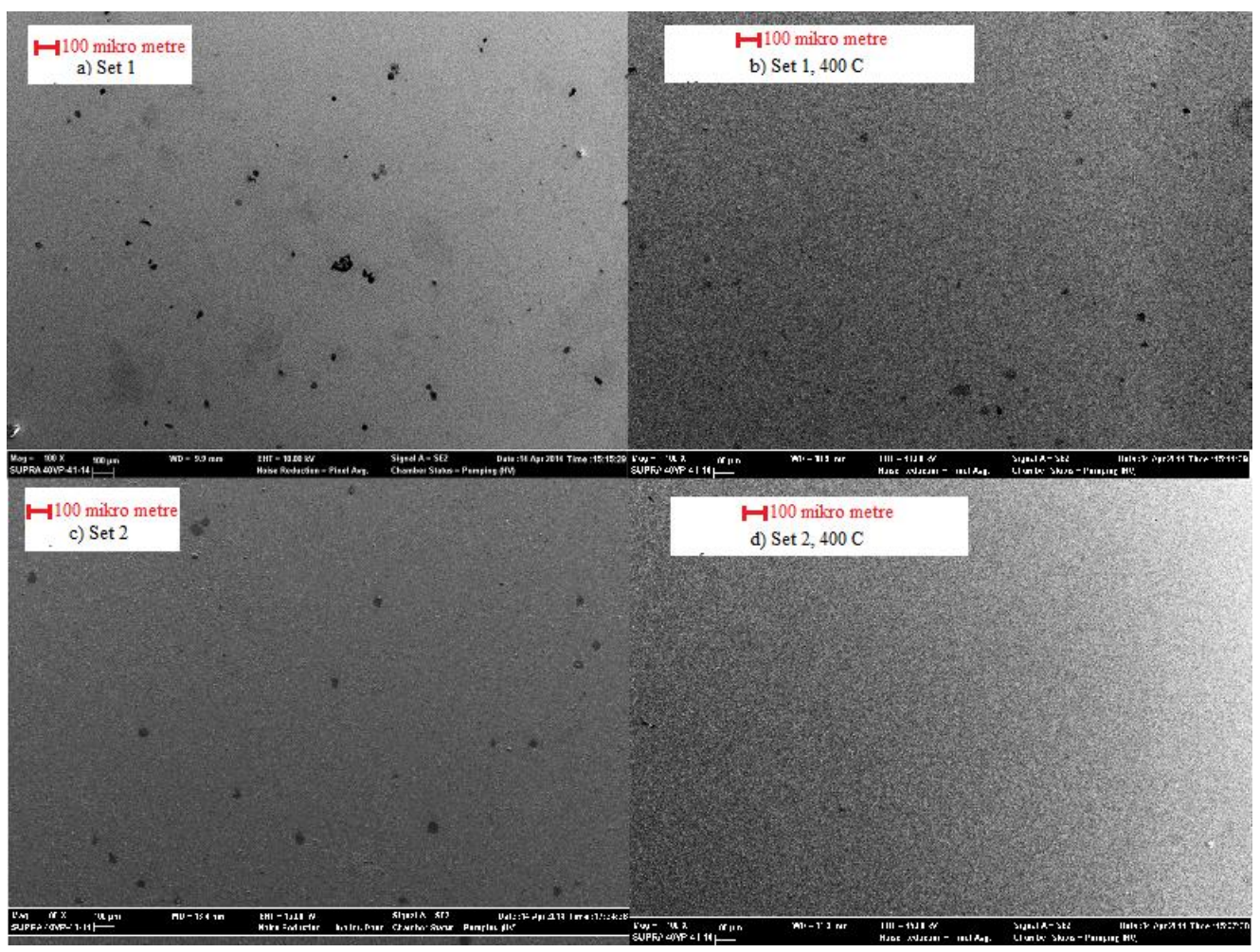

Şekil 4. Üretilen PbS ince filmlerin 100 büyütmedeki SEM görüntüleri

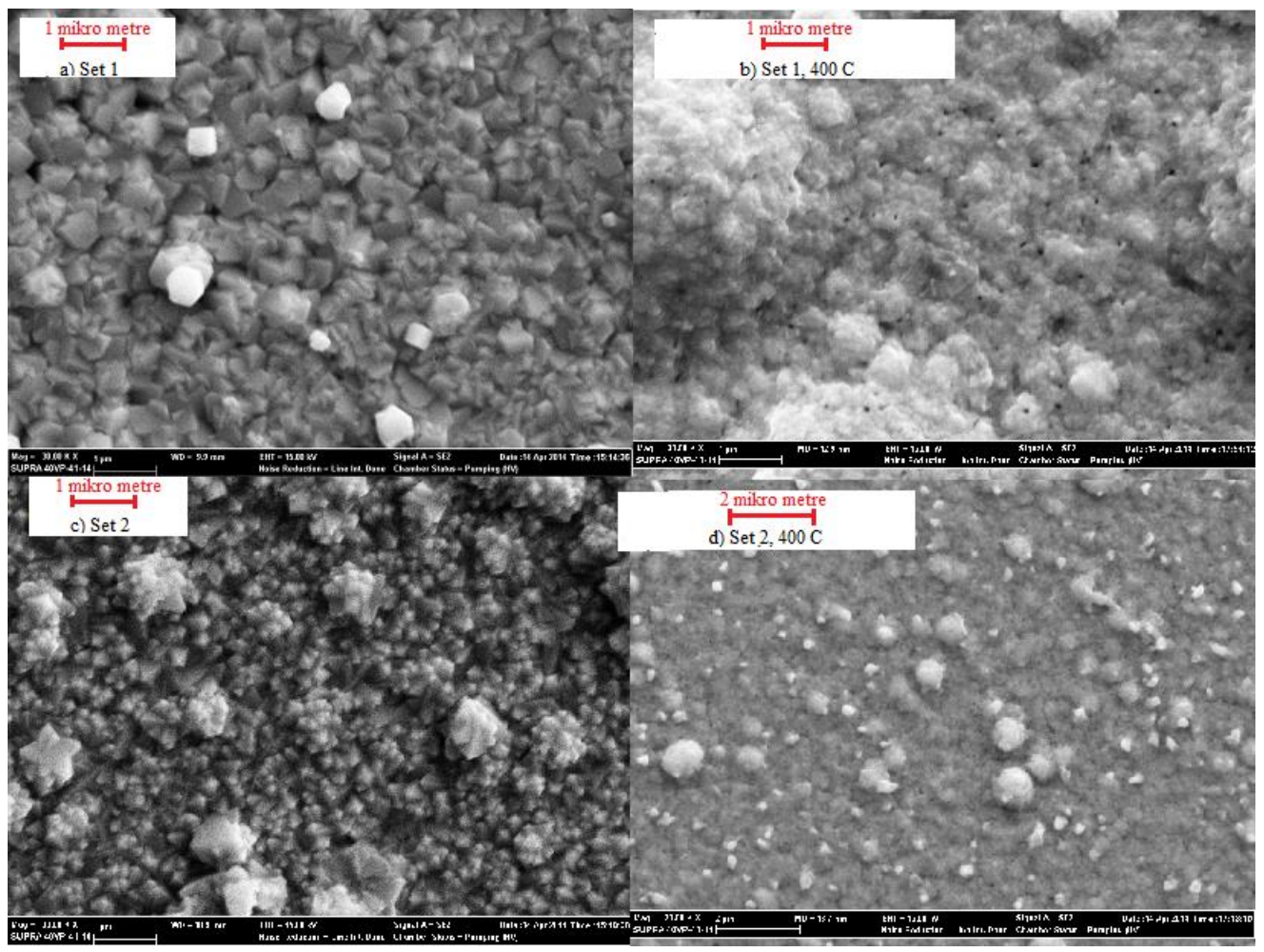

Şekil 5. Üretilen PbS ince filmlerin 30000 büyütmedeki SEM görüntüleri 
Şekil 5'de yer alan bütün PbS ince filmlerinin 30000 kat büyütmeleri incelendiğinde, Set1'den elde edilen $\mathrm{PbS}$ ince filminin polimorfik formda PbS kristallerinden oluştuğu görüldü. Ancak Set2'den elde edilen filmde $\mathrm{Na}_{2} \mathrm{SO}_{3}$ inhibitör eklenmesiyle yüzeydeki yapının değiştiği filmin pramit formunda $\mathrm{PbS}$ kristallerinden oluştuğu gözlendi.

Setl'den elde edilen filme $400{ }^{\circ} \mathrm{C}$ 'deki tavlama işlemi uygulandıktan sonra, ince filmin yüzeyindeki polimorfik PbS kristallerinin formu bozuldu ve bu filmin yüzeyinde pinhollerin var olduğu gözlendi.

Set2'den elde edilen filme $400{ }^{\circ} \mathrm{C}$ 'deki tavlama işlemi uygulandıktan sonra, ince filmin yüzeyi form değiştirdi. Pramidal yapıdaki bütün PbS kristalleri eriyip film yüzeyini kapladı. Söz konusu olan, bu pramit şeklindeki kristaller arasındaki boşluklar tavlamadan sonra tamamen kapandı.

\section{Tartışma}

$\mathrm{Bu}$ çalışmada üretilen bütün filmlerin tavlama işleminden sonra pik şiddetlerinin arttığı görüldü. Film kalınlıkları yaklaşık olarak aynı olmasına rağmen XRD pik şiddetlerin artması bu filmlerde kristallenmenin arttığını göstermektedir. Üretilen PbS ince filmlerin tavlama işleminden sonra yapılanma katsayısı değeri 1'den büyük tek bir yansıma düzleminin bulunduğu tespit edilmiştir. Bu düzlem, $30^{\circ}$ 'de gözüken $\mathrm{PbS}$ pikine karşılık gelen (002) düzlemidir. Ayrıca, tane büyüklüğü arttıkça, elde edilen X-ışınlarının kırınım deseninde yansıyan ışınların şiddetini gösteren piklerin de daraldığı görülmektedir. Set1'den elde edilen fillme tavlama işlemi uygulandıktan sonra ise, negatif stres değerleri tespit edildi. Bunun nedeninin, hesaplanan negatif mikro straine bağlı olarak PbS ince film üretimi esnasında meydana gelen baskı ve sıkışma gerginliği olduğu düşünülmektedir.

Üretilen PbS ince filmlerin SEM görüntüleri incelendiğinde ise, tavlama ile filmlerin yüzey yapılarının tamamen değiştiği ve deliklerin kaybolduğu görülmektedir. Ek olarak, $\mathrm{Na}_{2} \mathrm{SO}_{3}$ inhibitör eklenmesiyle $\mathrm{PbS}$ film yüzeyindeki yapının polimorfik formdan pramit formuna dönüştüğü gözlenmektedir.

\section{Kaynaklar}

[1] Fouda A, Marzook M, Abd El-Khalek H, Ahmed S, Eid E, El Basaty A. Structural and optical characterization of chemically deposited PbS thin films. Silicon 2016; 9(6), 809-816.

[2] Kotadiya N, Kothari A, Tiwari D, Chaudhuri T. Photoconducting nanocrystalline lead sulphide thin films obtained by chemical bath deposition. Applied Physics A 2012; 108(4), 819-824.

[3] Rajathi S, Kirubavathi K, Selvaraju K. Structural, morphological, optical and photoluminescence properties of nanocrystalline $\mathrm{PbS}$ thin films grown by chemical bath deposition. Arabian Journal of Chemistry 2017; 10(8), 11671174.

[4] Kumar S, Sharma TP, Zulfequar M, Husain M. Characterization of vacuum evaporated PbS thin films. Phys.B:Conden. Matter 2003; 325, 8-16.

[5] Partin DL, Heremans J, in: Moss TS, Mahajan S. (Eds.) Handbook on semiconductors. Elsevier 1994; 3, 369-380.

[6] Atwa DMM, Azzouz IM, Badr Y. Optical, structural and optoelectronic properties of pulsed laser deposition PbS Thin film. Appl.Phys.B 2011; 103, 161-164.

[7] Thangaraju B, Kaliannan P. Spray pyrolytically deposited PbS thin films. Semicond.Sci.Technol. 2000; 15, 849-853.

[8] Agarwal RC, Pillai PKC. Chemically sprayed PbS coatings for photothermal solar energy conversion. Applied Energy $1982 ; 11(1), 61-68$

[9] Hodes G, Semiconductor and ceramic nanoparticle films deposited by chemical bath deposition. Phys.Chem.Chem.Phys. 2007; 9, 2181-2196.

[10] Hodes G. Chemical solution deposition of semiconductor films. Marcel Dekker 2003; 125 (22), 6386-6837.

[11] Pawar SM, Pawar BS, Kim JH, Oh-Shim J, Lokhande C.D., Recent status of chemical bath deposited metal chalcogenide and metal oxide thin films. Cur. Appl. Phys. Rev. 2011; 11, 117-161.

[12] Enriquez JP, Mathew X. Influence of the thickness on structural, optical and electrical properties of chemical bath deposited CdS thin films. Solar Energy Materials and Solar Cells 2003; 76(3), 313-322.

[13] Popa, A, Lisca M, Stancu V, Buda M, Pentia E, Botila T. J. Optoelectron. Adv. Mater. 2006; 8, 43-45.

[14] Seghaier S, Kamoun N, Brini R, Amara AB. Structural and optical properties of PbS thin films deposited by chemical bath deposition. Mater. Chem. Phys. 2006; 97, 71-80.

[15] Abbas MM, Shehab AAb-M, Hassan, NA, Al-Samuraee AK. Effect of temperature and deposition time on the optical properties of chemically deposited nanostructure PbS thin films. Thin Solid Films 2011; 519, 4917-4922.

[16] Obaid AS, Mahdi MA, Hassan Z. Nanocoral PbS thin film growth by solid-vapor deposition. Optoelectron. Adv. Mater. - Rapid Commun 2012; 6, 422-426.

[17] Obaid AS, Mahdi MA, Ramizy Asmiet, Hassan Z. Structural properties of nanocrystalline PbS thin films prepared by chemical bath deposition method. Adv. Mater. Res. 2012; 364, 60-64.

[18] Preetha KC, Murali KV, Ragina AJ, Deepa K, Remadevi TL. Effect of cationic precursor ph on optical and transport properties of SILAR deposited nano crystalline PbS thin films. Curr. Appl. Phys. 2012; 12, 53-59. 
[19] Mathews N.R., Ángeles-Chávez C., Cortés-Jácome M.A., Toledo Antonio J.A., Physical properties of pulse electrodeposited lead sulfide thin films. Electrochim.Acta. 2013; 99, 76-84.

[20] Sharan M, Ramaiah KS, Kumar M, Neumann-Spallart M, Levy Clement C. Electrodeposition of lead sulphide in Acidic medium. J. Electroanal. Chem 1997; 436, 49-52.

[21] Takahashi M, Ohshima Y, Nagata K, Furcita S. Electrodeposition of PbS films from acidic solution. J. Electroanal. Chem. 1993; 359, 281-286.

[22] Salavati-Niasari M, Ghanbari D, Loghman-Estarki MR, Star-shaped PbS nanocrystals prepared by hydrothermal process in the presence of thioglycolic acid. Polyhedron 2012; 35, 149-153.

[23] Seghaier S, Kamoun N, Brini R, Amara AB. Structural and optical properties of PbS thin films deposited by chemical bath deposition. Materials Chemistry and Physics 2006; 97,71-80.

[24] Sonavane DK, Jare SK, Kathare RV, Bulakhe RN, Shim JJ. Chemical synthesis of PbS thin films and its physicochemical properties. Materials Today: Proceedings 2018; 5, 7743-7747.

[25] Seghaier S, Kamoun N, Guasch C, Zellama K, Structural and optical properties of PbS thin films grown by chemical bath deposition. AIP Conference Proceedings 2007; 935(1), 143-148

[26] Pentia E, Pintilie L, Botila T, Pintilie I, Chaparro A, Maffiotte C. Bi Influence on growth and physical properties of chemical deposited PbS films.Thin Solid Films 2003; 434(1-2),162-170.

[27] Ramírez-Ceja D, González L, Escorcia-García J, Martínez-Enríquez A. Characterization of PbS thin films obtained by chemical bath at low temperature using sodium citrate as complexing agent. MRS Advances 2016; 1(37), 2623-2628.

[28] Altıkka B., Baykul MC., Altıkka MR., Some physical effects of reaction rate on PbS thin films obtained by chemical bath deposition. Journal of crystal growth 2013;38, 50-54.

[29] Soetedjo H, Siswanto B, Aziz I, Sudjatmoko. Deposition of Cu-doped PbS thin films with low resistivity using DC sputtering. Results in Physics 2018; 8, 903-907.

[30] Bhowmik R, Murty M, Srinadhu E. Magnetic modulation in mechanical alloyed $\mathrm{Cr}_{1.4} \mathrm{Fe}_{0.6} \mathrm{O}_{3}$ oxide. PMC Physics B 2008; 1(1), 20.

[31] Hussain A, Begum A, Rahman A. Characterization of nanocrystalline lead sulphide thin films prepared by chemical bath deposition technique. Arabian Journal for Science and Engineering 2012; 38(1), 169-174.

[32] Obaid A, Mahdi M, Hassan Z, Bououdina M. PbS nanocrystal solar cells fabricated using microwave-assisted chemical bath deposition. International Journal of Hydrogen Energy 2013; 38(2), 807-815.

[33] Kumbhakar P, Kole AK. Cubic-to-hexagonal phase transition and optical properties of chemically synthesized ZnS nanocrystals. Results in Physics 2012; 2, 150-155. 